\title{
Alaskan fishing community revenues and the stabilizing role of fishing portfolios
}

\author{
Suresh Andrew Sethi ${ }^{\mathrm{a}, *}$, Matthew Reimer ${ }^{\mathrm{b}}$, Gunnar Knapp ${ }^{\mathrm{b}, 1}$ \\ a Alaska Pacific University, Department of Environmental Science, 4101 University Drive, Anchorage, AK 99508, United States \\ ${ }^{\mathrm{b}}$ University of Alaska-Anchorage, Institute of Social and Economic Research 3211 Providence Drive, Anchorage, AK 99508, United States
}

\section{A R T I C L E I N F O}

\section{Article history:}

Received 18 January 2014

Received in revised form

20 March 2014

Accepted 20 March 2014

Available online 12 April 2014

\section{Keywords:}

Fishing community

Portfolio

Economic risk

Alaska

\begin{abstract}
A B S T R A C T
Fishing communities are subject to economic risk as the commercial fisheries they rely on are intrinsically volatile. The degree to which a community is exposed to economic risk depends on a community's ability to confront and/or alter its exposure to volatile fishery conditions through riskreduction mechanisms. In this article, economic risk - as measured by community-level fishing gross revenues variability - is characterized across Alaskan fishing communities over the past two decades, and exploratory analyses are conducted to identify associations between community attributes and revenues variability. Results show that communities' fishing portfolio size and diversification are strongly related to fishing revenues variability. Communities with larger and/or more diverse fishing portfolios experience lower fishing revenues variability. Portfolio size and diversification appear to be related to the number of local fisheries, indicating that communities' portfolios may be constrained to the set of local fisheries. Hotspots of relatively higher fishing revenues variability for communities in north and west Alaska were identified, mirroring the spatial distribution of fishery-specific ex-vessel revenues variability. This overall pattern suggests that a community's fishing portfolio - and hence its exposure to risk - may be "predetermined" by its location, thereby limiting the policy options available to promote economic stability through larger and/or more diverse fishing portfolios. For such communities, diversifying income across non-fishing sectors may be an important risk reduction strategy, provided any potential negative cross-sector externalities are addressed.
\end{abstract}

(c) 2014 Elsevier Ltd. All rights reserved.

\section{Introduction}

While the majority of Alaskan commercial fisheries are sustainably managed [1], Alaskan fishing communities experience a range of social, economic, environmental, and biological stressors. The 1996 re-authorization of the Magnuson-Stevens Fishery Conservation and Management Act requires that fisheries managers consider the impacts of fisheries regulations on fishing communities [2], and a pressing concern in fisheries management is to understand the current status of fishing communities and the mechanisms that drive community dynamics. Particular interest lies in identifying which characteristics, if any, are associated with a community's ability to withstand and adapt to the range of stressors affecting fishing communities [3,4]. With knowledge of attributes associated with fishing community resilience, managers can identify potentially controllable factors through which policy goals for sustainable fishing communities can be achieved, as well

\footnotetext{
* Corresponding author. Tel.: +1907 3993998.

E-mail addresses: sasethi@gmail.com (S.A. Sethi),

mnreimer@uaa.alaska.edu (M. Reimer), gunnar.knapp@uaa.alaska.edu (G. Knapp).

1 Tel.: +1907 7867717 .
}

as highlight communities that are particularly vulnerable as candidates for more proactive and targeted policies.

Commercial fisheries upon which fishing communities rely are intrinsically volatile due to variable market conditions, fluctuating catches and stock dynamics, changes to fishery regulations, and environmental change [5-7]. It follows that communities that are dependent on revenue flows from these fisheries may be subject to significant economic risk-communities are more likely to experience periodic low revenue flows when fishing catches and prices are highly variable due to unpredictable fishery conditions. The degree to which a community is subject to economic variability, however, depends on a community's ability to confront and/or alter its exposure to volatile fishery conditions through risk-reduction mechanisms. For instance, a community may experience lower exposure to volatile fishery conditions if its revenues flows are diversified across a variety of fisheries, similar to a crop diversification strategy practiced by farmers [8,9]. However, fishing communities may differ in the opportunities available to diversify their portfolio of fishing revenue flows due to differences in their proximity to commercial fisheries or differences in fleet characteristics which promote or constrain participation in diversified fisheries, inter alia. 
Fishing revenues are only one of the multiple dimensions which make up fishing communities; however, characterizing the status and drivers of economic variability is particularly important for communities whose economic base relies on the inflow of commercial fishing revenues, like many isolated fishing communities in Alaska [6,10-12]. The degree to which community-level gross fishing revenues have varied over recent history has not been systematically characterized across the state. For example, do communities across the state experience similar revenue variability, or are there hotspots of high or low variability?

In this paper, we conduct an exploratory analysis of observed levels of risk - i.e. the chance of experiencing a bad revenues outcome - in Alaskan fishing communities with the following three objectives: (i) characterize community-level fishing gross revenues risk across Alaskan fishing communities over the past two decades; (ii) identify associations between fishing community attributes and revenues risk, with a particular focus on the influence of fishing portfolios in mitigating risk; and (iii) discuss community attributes associated with fishing revenue variability and fishing portfolio composition in the context of natural resource management policy and future research directions to promote understanding of fishing community dynamics.

Diversifying fishing activity over a variety of fisheries is an important mechanism through which fishing communities may be able to reduce economic risk [13-16]. The benefits of having a diversified portfolio of fishery revenue flows is analogous to the benefits of a diversified portfolio of risky assets; diversification can lower the variance - and thus the risk - of a portfolio's return, potentially below the variance of the least risky asset. In general, the larger the number of assets in a portfolio, the greater the benefits of diversification [17]; however, the effectiveness of portfolio diversification depends on the correlation between asset returns. The benefits of diversification are enhanced if assets are negatively correlated, noting that risk reduction can still occur with positively correlated assets cf. [18]. Commercial fishermen in Alaska have a wide range of fisheries in which they can participate, with each fishery differing by its target species (e.g. crab, herring, salmon, halibut), gear type (e.g. purse seine, gillnet, pot gear), and geographic location (e.g. Bristol Bay, Prince William Sound, Southeast Alaska). The degree of diversification in a community's fishery portfolio is therefore determined by the variety of commercial fisheries in which its residents participate.

In a separate analysis, Sethi et al. [19] collated a database of community-level metrics which provides information on the status of multiple dimensions of fishing communities. Metrics are partially or fully available for 324 Alaskan fishing communities over 1980-2010 and include community-level information on population, fishing opportunities, fleets, fishermen experience, and landings. These metrics are used in exploratory analysis of the relationship between variability in community-level fishing gross revenues and the following fishing community attributes: the size and diversity of a community's portfolio of fishing revenue flows, investment into fishing vessels, geographic location and proximity to fishing opportunities, and community demographics such as population size and fishing tenure. While the set of metrics used in this analysis may not fully characterize the myriad dimensions which drive fishing communities' revenue variability, we contend that they provide a good starting set of attributes for understanding the mechanisms underlying community-level economic risk. As an example, it is expected that fishing communities with larger fleet investments and more fishing experience would encounter less revenue variability since newer, larger, and better equipped vessels with more experienced captains may be able to take advantage of peripheral fishing areas and occasions - and thus revenue opportunities - that they would not be able to otherwise exploit.
Regression analyses indicated that communities' fishing portfolio size and diversification were strongly related to communitylevel fishing gross revenues variability, controlling for community size, fleet investments, and fishermen experience. Policies which restrict fishermen's and thus communities' abilities to diversify revenues flows over multiple fisheries could therefore lead to increased risk exposure. Portfolio size and diversification appeared to be related to the number of local fisheries, indicating that the composition of communities' fishing portfolios may be constrained to the set of local fisheries. Our results indicated hotspots of high community-level fishing gross revenues variability in north and west Alaska, with relatively lower community levels fishing revenues variability in the southern and eastern parts of the state, mirroring the spatial distribution of fisheryspecific ex-vessel revenues variability [5]. This overall pattern suggests that a community's fishing portfolio - and hence its exposure to risk - may be "predetermined" by its location, thereby limiting the policy options available to promote economic stability through larger and/or more diverse fishing portfolios. For such communities, diversifying income across non-fishing sectors may be an important risk reduction strategy, provided any potential negative cross-sector externalities are addressed.

\section{Methods}

\subsection{Definitions and data}

Residents of Alaskan communities have a variety of state- and federally-managed commercial fisheries in which they can participate, spanning multiple targeted species, gear types, and management institutions. Commercial fisheries managed by the State of Alaska include all fisheries that occur within 3 nautical miles (nm) from shore and a subset of fisheries in federal waters $>3 \mathrm{~nm}$ offshore within the U.S. exclusive economic zone but for which management is delegated to the State (e.g. crab fisheries). State-managed fisheries are dominated by limited entry programs, the majority of which allow the transfer of permits between individuals through sale or bequest [20]. At present, permit leases for state-managed fisheries are not allowed except in medical emergencies. U.S. federally-managed fisheries in Alaskan waters occur greater than three nautical miles offshore and are managed by some form of limited entry (e.g. the Central Gulf of Alaska groundfish trawl fleet) or catch share (e.g. the sablefish Individual Fishing Quota fleet) program. State- and federally-managed fisheries off Alaska are prosecuted by a wide variety of vessels, ranging from small skiffs using longlines to catch halibut, to large catcher processors which catch and process pollock in the Bering Sea.

Under State law, Alaskan commercial fisheries are stipulated by taxa (either a species such as Pacific herring, Clupea pallasii, or group such as Pacific salmon, Oncorhynchus spp.), fishing district, and gear type. Any individual that partakes in commercial activity in state waters, including harvesting or landing catch from a stateor federally-managed fishery, requires a fishery-specific permit issued by the Alaska Commercial Fisheries Entry Commission (CFEC). For example, a S03T CFEC permit is required to operate in the salmon (S) drift gillnet (03) fishery in Bristol Bay (T), Alaska. Overall, 20,275 CFEC permits were issued across 205 fisheries in Alaska in 2010, 15,475 of which were held by Alaskan residents with the remainder owned by non-Alaskan U.S. citizens. The CFEC tracks commercial landings by permit, permit ownership, and permit-holder residency information, and publishes data on fishing vessels registered in the State (e.g. length and engine horsepower). The CFEC assigns each permit-holder a unique file number which can be used to cross-reference residency, permit ownership, and vessel information. As such, the set of fishing 
opportunities within a community can be reconstructed by collating all CFEC commercial fishing permits registered to participants who declare their home address in a given community.

We obtained community-level gross fishing revenues data from publicly available databases published by the CFEC, which were discounted to 2010USD using the Anchorage Consumer Price Index. These revenues represent the sum of annual gross fishing revenues attributable to CFEC permits registered to a given community. Permitholders may participate in and make landings in fisheries not local to their community of residence. In these cases, some landings revenues may ultimately remain at the place of the fishery, for example through municipal landings taxes if levied or through local fleet services; however, we presume the bulk of fishing revenues return to fishermen's communities of residence. CFEC community-level fisheries revenues data do not include catches in the U.S. federally-managed groundfish fisheries for which the harvest is not landed in an Alaskan port. The number of such fisheries across the state are few and are dominated by large catcher processors owned by out-of-state firms; thus, their direct impact is restricted to a small number of Alaskan fishing communities (e.g. Dutch Harbor and Kodiak). Finally, State confidentiality restrictions prevent publication of catch or revenues information for fisheries for which there are fewer than four participants. As a result, these very small fisheries are excluded from our data.

We define an Alaskan community as a named settlement as recorded by the Alaska Division of Community and Regional Affairs (available at www.commerce.state.ak.us), and define a "fishing community" as a community with fishing rights and which derives some economic or social benefit from commercial fishing (cf. U.S. Magnuson-Stevens Fishery Conservation and Management Act; [2]). The Community and Regional Affairs division publishes a list of 396 communities as having existed in Alaska since statehood in 1959; however, complete or partial commercial fishing revenues, commercial fishing permit, permitholder, and vessel information necessary to construct fishing community attribute metrics were available for a subset of 324 communities.

Fishing community attribute information was taken from publicly available data sources including the CFEC (www.cfec.state.ak; landings gross revenues by community, community attributes), the U.S. decennial census data (www.census.gov) as published by the Alaska Division of Community and Regional Affairs (available at www.commerce.state.ak.us; community attributes), and the U.S. Bureau of Labor Statistics (available at www.bls.gov; Anchorage Consumer Price Index for revenues deflation). Fishing community attribute information is available on an annual basis (further details provided in [19]).

Fishing community attributes proposed as potentially being associated with fishing community gross revenues variability represent a balance between a priori research questions (see above) and data availability. Measured community attributes considered for inclusion into subsequent regression modeling included information on: (i) community size: population; (ii) and (iii) fishing portfolios: number of different fisheries in which community members participated and Simpson's diversity index [21] for the portfolio of active fisheries; (iv) fleet investment: sum of length of vessels registered to a community per active fisherman; ( $v$ ) a proxy for fishermen skill and experience: years of commercial fishing tenure (years of owning at least one CFEC fishing permit) for permitholders in a community; and (vi) and (vii) location: community latitude and longitude.

We considered a community fishing portfolio to be the set of fisheries in which members of the community operate, where a portfolio "asset" is a fishery. Because catch and price outcomes are stochastic, fishing communities do not directly select their fishing revenues outcomes; however, fishing community members do make decisions to seek out permits in one or more fisheries and, if they have access to multiple permits, in which fisheries to participate. Thus, in a given year, the number of a community's active permits participating in a given fishery represents the ex ante weighting for that "asset" in a fishing portfolio, whereas the sum of annual landings gross revenues generated from community members' participation in the fishery represents an ex post portfolio outcome. For what follows, portfolio size is defined as the number of different fisheries in which residents of a community participate, and portfolio diversification is measured with Simpson's diversity index as:

$\sum_{i=1}^{k} p_{i}^{2}$

for $k$ active fisheries in a community where $p_{i}$ is either the proportion of total active permits in a community participating in fishery $i$ when considering ex ante portfolio diversification (not all permits are fished in every year), and the proportion of a community's annual fishing revenues attributable to fishery $i$ when considering ex post portfolio diversification. ${ }^{2}$ Simpson's diversity index ranges from 0 to 1.0 , with higher values indicating less diversification. While ex ante portfolio construction reflects communities' anticipation of fishing outcomes, thereby influencing community fishing gross revenues by defining the number and weightings of active fisheries in a portfolio, financial risk is ultimately the result of realized revenue outcomes. For regression analyses (see below), we therefore chose to examine the association between community-level fishing gross revenues and ex post portfolio diversification; regression analyses using the ex ante version of portfolio diversification, are provided in the online Supplementary materials (Fig. S1) and resulted in analogous conclusions to those presented below.

\subsection{Community-level annual fishing revenues variability measures}

We characterized annual revenues variability over a twenty year period from 1990-2010. Variability was measured using the coefficient of variation (CV) and conditional value at risk (CVaR; e.g. [22,23]; see below), and implemented using custom functions written in R [24] following Sethi and Dalton [25]. The length and timing of the study period was chosen based upon several factors. First, simulation analyses with data modeled after historical Alaskan commercial fisheries revenues suggest that a sample size of at least 10-15 data points is desirable for characterizing variability over a time period using the CV and CVaR [25]. We therefore restricted our analysis of gross revenues variability to those communities with at least 10 years of revenues data over 1990-2010, resulting in 110 communities with sufficient revenues data. Second, the study period occurs after the last major Pacific decadal oscillation and the associated reorganization of Alaskan marine ecosystems [26]. Third, state-wide community analyses [19] indicate that most communities experienced a peak in catch and revenues in the later 1980s; the period of 1990 onwards captures the decline from the peak as well as a more recent recovery period and provides good contrast to identify whether

\footnotetext{
${ }^{2}$ Note, fishermen may operate in more than one fishery in a community, but because commercial fishing permits are specific to a taxa-gear-area combination, the ex ante portfolio diversification measure does not double count active permits. For example, consider a small community with 10 active permits in one fishery, 5 active permits in another, and 5 active permits in a third and final fishery. While some permitholders may operate in multiple fisheries in the community, a unique permit must be employed for each respective fishery, such that $\boldsymbol{p}=\{10 / 20,5 / 20,5$ $20\}=\{0.5,0.25,0.25\}$ In this case, the ex ante portfolio diversification measures is $0.5^{2}+0.25^{2}+0.25^{2}=0.375$.
} 
some communities experience less drastic swings in revenues over this period.

The $C V, \nu$, is defined as:

$\nu=\frac{\sigma}{\mu}$

where $\sigma$ and $\mu$ are the standard deviation and mean, respectively, of a random variable (here, a community's annual fishing gross revenues). The CVaR, $\phi$, focuses on the magnitude of extreme bad events. It is the expected outcome conditional on being in the $\alpha \%$ worst case scenarios, i.e. $\alpha \%$ worst realizations of outcomes for a random variable:

$\phi(R, \alpha)=E[R \mid F(r)<\alpha]=\frac{1}{\alpha} \int_{r<F^{-1}(\alpha)} r f(r) d r$

where $F$ and $F^{-1}$ are the cumulative and inverse cumulative probability functions for the distribution describing the outcome behavior of the random variable $R$ (with outcomes $r$ ). We used an alpha level of $25 \%$. Analogous to the coefficient of variation, CVaR was scaled to the sample mean to facilitate comparison across communities with revenues of different scales. Finally, the CVaR measure in mean units was subtracted from 1.0 to indicate the expected downside outcome distance from the mean, in mean units. Scaled CVaR, $\bar{\phi}$, is:

$\bar{\phi}=1-\frac{\phi}{\bar{x}}$

where $\bar{x}$ is the sample mean for a series of revenues. Scaled CVaR ranges on $[0,1]$. For example, calculated as above using $25 \% \mathrm{CVaR}$ (henceforth referred to as $\mathrm{CVaR}_{25}$ ), a $\bar{\phi}$ measure of 0.55 indicates that an outcome that is $55 \%$ less than the long term mean is expected in one in four years.

\subsection{Statistical analyses}

We analyzed the association between community attributes and fishing gross revenues variability as measured by $\mathrm{CV}$ and $\mathrm{CVaR}_{25}$ using random forest regression $[27,28]$. Separate regression analyses were carried out for the two variability measures. Community attribute information is available on an annual basis and we used the arithmetic mean value across the study period to generate a single data point per community per attribute for subsequent regression. Because risk measure information - i.e. the dependent variable in regression analyses - represents a summary statistic across a set of annual data for a community, panel methods of regression were not available [29]. Only those communities with at least seven years of regressor data over the study period for all attributes under consideration in the study were retained for regression modeling. Thus, regression analyses were conducted with the subset of fishing communities satisfying both revenues variability ( 10 or more data points) and attribute data ( 7 or more data points) thresholds, for a total of 84 communities. We also conducted analyses using an attribute threshold of 10 years, which reduced the subset of permissible communities to 79 , and found analogous regression and model selection results to those reported below (results not shown but available from the authors upon request).

Random forest regression was employed because the estimator does not require any parametric distribution assumption be made for the response variable (here, $\mathrm{CV}$ or $\mathrm{CVaR}_{25}$ ) and because it is a flexible estimator which can elucidate complex potentially nonlinear relationships between regressors and the response variable [5]. In order to pick a parsimonious best approximating model, we used a model selection routine based on cross validation and random forest variable importance as detailed in Sethi et al. [5]. Briefly, the procedure works as follows:
Step 1: Fit the global model using the full set of community attributes as predictor variables, and compute permutationbased random forest variable importance measures which assess the relative importance of different predictors in the model in explaining variability in the response data (revenues variability). Also compute the mean squared error for model predictions in the random forest fitting procedure.

Step 2: Drop the least important variable and fit the model.

Step 3: Iterate Step 2 until only two variables remain.

Step 4: Choose as the best model the largest model within +1 standard deviation from the lowest mean square error model. This selection procedure results in a balance between model complexity and model fit, while accounting for variability in generating the variable importance measure in nonparametric regression $[28,30,31]$.

The relationships between predictors and the response data, as estimated by the best performing random forest regression model, are represented visually through partial dependence plots $[32,33]$. A partial dependence plot depicts the marginal relationship between a single regressor and the response variable by integrating over all model predictions while holding the variable of interest constant at a prescribed value. This procedure is repeated for all values of the predictor variable of interest. The results are subsequently plotted to characterize the marginal relationship between the predictor variable of interest and the dependent variable while accounting for the influence of all other predictor variables. We implemented the random forest regressions with the randomForest package [33] in the $\mathrm{R}$ statistical programming environment [24]. We set the number of trees in the random forest to 50,000, the number of variables to try at splits within regression trees to 3 , and observed data were sampled without replacement during forest construction.

Regression analyses considered models without interactions or higher order terms. Modeling began by first examining regressors for collinearity. The total number of active fisheries in a community (i.e. fishing community portfolio size) was moderately correlated with population (correlation $=0.70$ ) and Simpson's index for fishing portfolio (ex post) diversification (correlation $=-0.78$ ); however we chose to retain total number of active fisheries because collinearity was not severe and because it plays a central role in exploring the relationship between portfolio size and diversification with fishing revenues variability.

\section{Results}

\subsection{Revenues variability summary}

Alaskan fishing communities experienced a wide range of fishing gross variability over 1990-2010 (Fig. 1; Table S1). The three most stable communities - as ranked by both $\mathrm{CV}$ and $\mathrm{CVaR}_{25}-$ had community-level annual gross revenues CV of $15 \%$ or less and $\mathrm{CVaR}_{25}$ of $20 \%$ or less, the latter indicating that for those communities, a worst case outcome was characterized as $<20 \%$ reduction from the long term mean in one in four years (i.e. $80 \%$ of mean or better expected in 3 of four years). The three least stable communities had gross revenues CV above $120 \%$ and $\mathrm{CVaR}_{25}$ above $90 \%$, the latter indicating that in one in four years, these communities expect annual fishing gross revenues to be $90 \%$ below the long term mean level.

By visual inspection (Fig. 1; Table S1), communities in the southeast region of the state tend to experience less risk in terms of the occurrence of both typical and extreme bad events. Indeed, four of the top five most stable communities in terms of gross revenues $\mathrm{CV}$, and all five of the top five most stable communities 

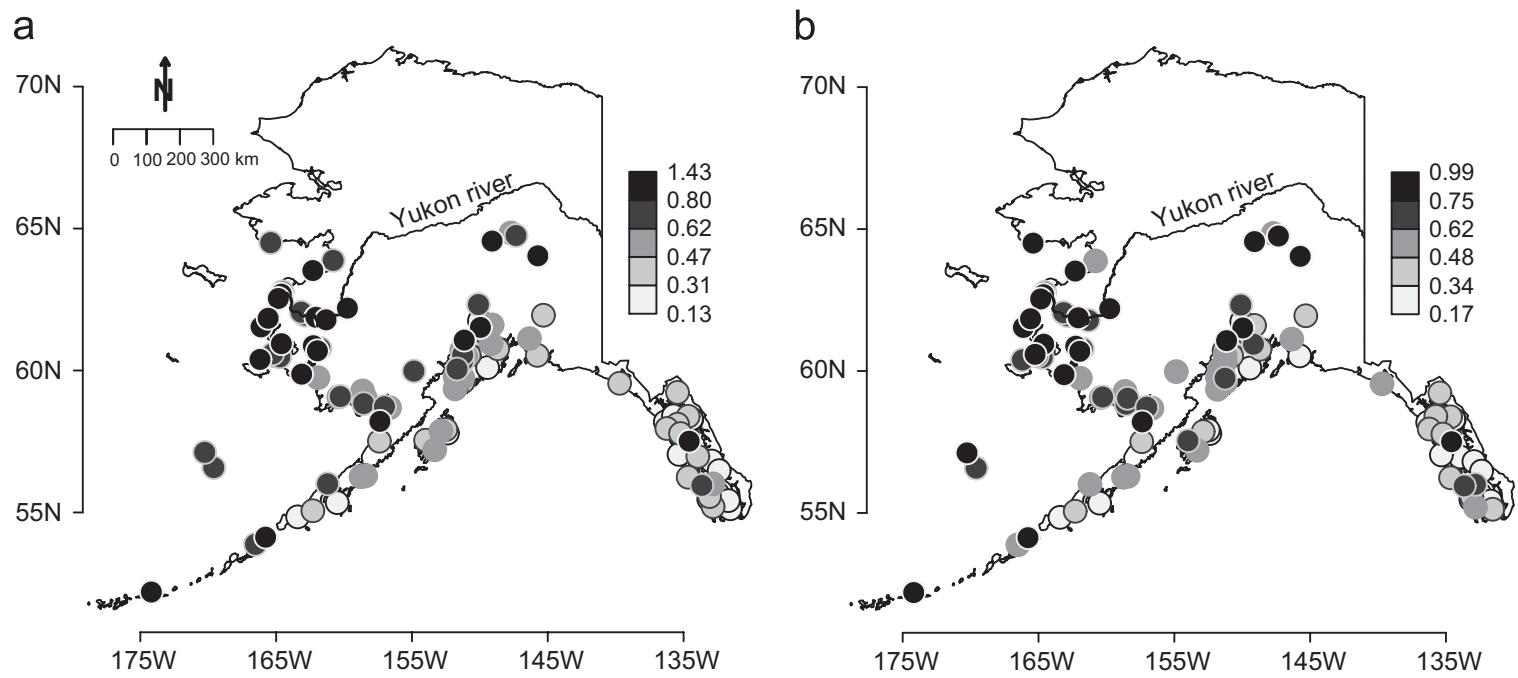

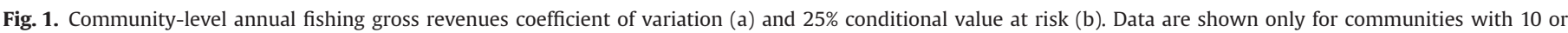

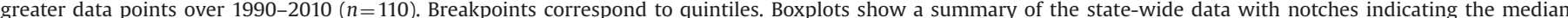
metric value and 95\% confidence interval [34].

in terms of $\mathrm{CVaR}_{25}$ were from the southeast region of the state. In contrast, the least stable communities were dispersed across the northern and western parts of the state.

\subsection{Regression analysis}

Model selection supported dropping the proxy for fishermen experience and skill (i.e. mean tenure in commercial fisheries) for both gross revenues $\mathrm{CVaR}_{25}$ and $\mathrm{CV}$ information, but retention of all other covariates. The best fit models explained $64.2 \%$ and $55.5 \%$ of the variation in fishing gross revenues $\mathrm{CVaR}_{25}$ and $\mathrm{CV}$ information amongst communities, respectively.

Both regression analyses indicate that the size of communities' active fishing portfolios (Fig. 2a, number of fisheries) and the ex post degree of diversification of fishing portfolios (Simpson's diversity index of fishing gross revenues, Fig. 2b) had the strongest association with community-level annual fishing gross revenues variability. After controlling for location, population size, and fleet investments, regression models suggest a strong effect of declining revenues variability with increasing fishing portfolio size and diversification. Partial dependence plots indicate that an increase from a small number of active fisheries (e.g. from 2 to 10 fisheries) has the largest impact on reducing risk (Fig. 2a). In contrast, the effect of portfolio diversification appears to be more approximately linear with each additional increment of diversification resulting in comparable variability reduction (Fig. 2 b). All things the same, regression results suggest that a community with 5 active fisheries in its portfolio would have 35\% greater gross revenues $\mathrm{CVaR}_{25}$ and $20 \%$ greater gross revenues $\mathrm{CV}$ than a community with 25 active fisheries. Similarly, a minimallydiversified community would have $30 \%$ greater gross revenues $\mathrm{CVaR}_{25}$ and $25 \%$ greater gross revenues $\mathrm{CV}$ than a maximallydiversified community.

The third strongest association identified was between communities' location and gross revenues variability, with an increasing variability gradient moving west across the state (Fig. 2c), although partial dependence plots indicated a threshold effect where the association of longitude with revenues variability became weak for communities east of about $150{ }^{\circ} \mathrm{W}$ (approximate longitude for Anchorage, AK). Regression analyses also supported an increasing variability gradient moving north across the state, however, the association was considerably weaker than for an east to west gradient (Fig. 2e).
Communities' investments into fleets, as measured as the sum of vessel length per active fishermen, were also associated with gross revenues variability, where communities with more boat per fisherman were associated with lower gross fishing revenues variability (Fig. 2d, sum vessel feet/fisherman). Community size as measured as (natural $\log$ ) population was retained in both models for fishing gross revenues $\mathrm{CVaR}_{25}$ and $\mathrm{CV}$; however, the predicted association was weak (Fig. $2 \mathrm{f}$ ), indicating that all things the same, community-level fishing gross revenues variability and population size were largely decoupled.

\section{Discussion}

A growing body of work has demonstrated that portfolio size and diversification play a role in stabilizing output, such as revenues or biomass, in natural resource systems [13,35-37]. The gross fishing revenues variability communities experienced over the 1990-2010 study period ranged dramatically across the State, and evidence based upon the sample of fishing communities in this study indicated that both portfolio size and diversification play important roles in stabilizing community-level fishing gross revenues. Certainly portfolio size and diversification are not the only factors which influence community-level fishing gross revenues variability-in fact, we found evidence that communities with more invested into their fishing fleets were associated with lower fishing gross revenues variability, potentially as bigger and more numerous boats allow for greater catching power and/or access to a wider range of fishing revenues opportunities. After controlling for the effects of population size, investments into fleets, and geographic location, however, portfolio size and diversification remained most strongly associated with community-level fishing revenues variability. Population size and operator skill had little to no association with community-level fishing gross revenues variability.

While the benefits of larger and more diversified portfolios for stabilizing revenues flows are clear, there are a number of reasons why fishing communities may differ in the size and diversity of their fishing revenue portfolios, chiefly that portfolio makeup and performance may be constrained by the set of local fishing opportunities. Fishermen can travel to operate in fisheries outside of their local community of residence, providing a strategy to expand and diversify communities' fishing portfolios beyond the set of local fisheries; however this strategy incurs additional travel 
a

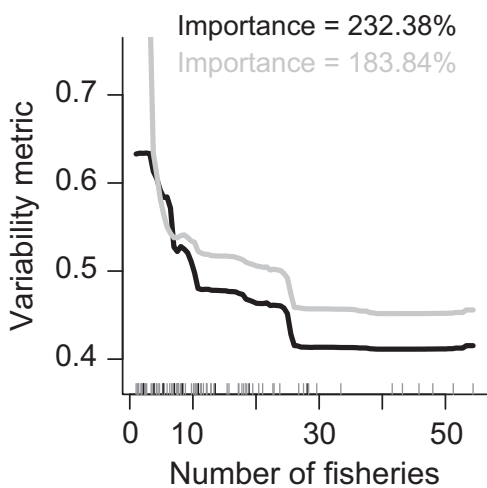

d

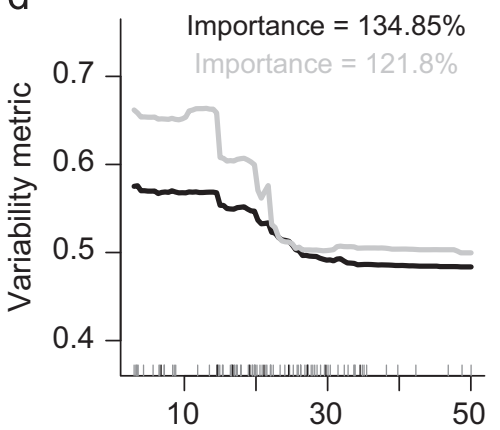

Sum vessel feet / fisherman b

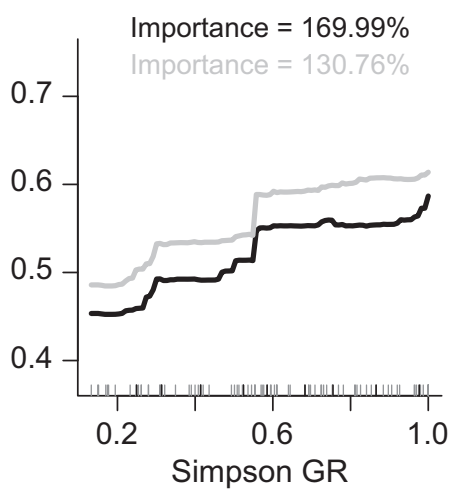

e

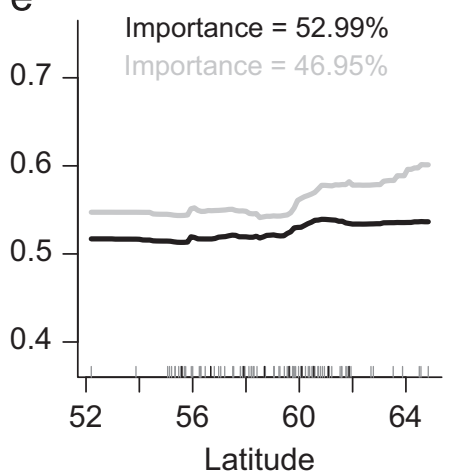

C

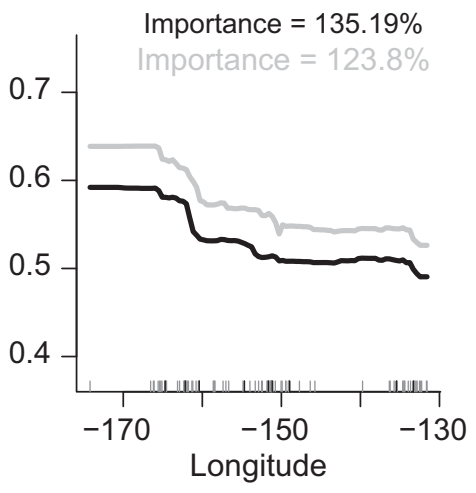

f

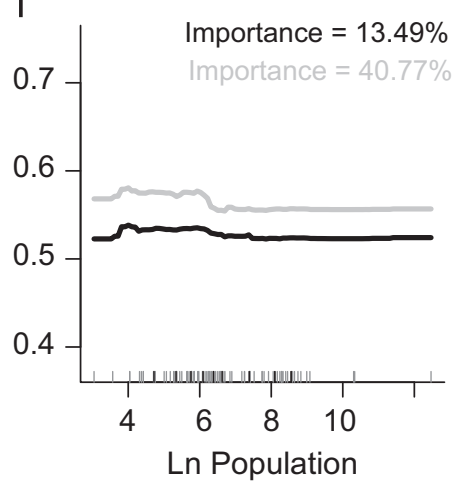

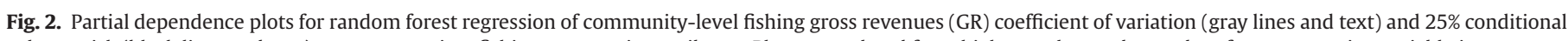

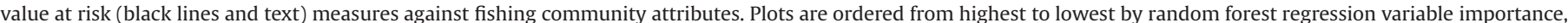

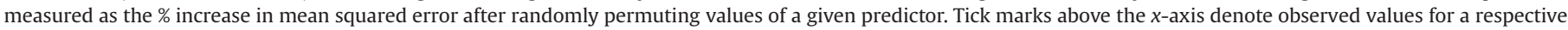

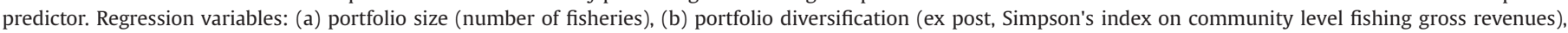

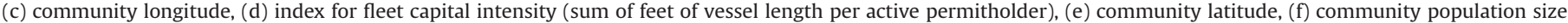
(natural log of population).

and time costs, particularly for remote communities or fishing locations, and may require larger seaworthy vessels. When mapped across the State, the size of community-level fishing portfolios appears to be related to the number of local fisheries, with communities inland on rivers and communities in northern and western parts of the state having smaller portfolios than communities in the fisheries-rich southern and eastern regions of the state (Fig. 3). Regional patterns in portfolio diversification also follow this trend (Fig. 4), suggesting that communities' fishing portfolios are influenced by the set of local fisheries available for participation. It follows that communities' fishing revenue variability will be largely influenced by the variability patterns exhibited by local fisheries, as suggested by the regional differences in our regression analyses, with southern and eastern communities tending to have more stable revenues than northern and western communities. Indeed, this spatial gradient amongst communities' revenues variability mirrors trends in risk at the fishery level whereby northern and western fisheries tend to be more volatile than southern and eastern fisheries [5].

The metrics used in this analysis may not fully characterize the multiple dimensions in which fishing portfolios may drive fishing communities' revenue variability. For instance, portfolio theory suggests that an "active" portfolio management style - whereby portfolios are often revised in response to market conditions - may outperform a "passive" management style if active managers are able to consistently select assets that outperform the market [38]. In the context of this study, some Alaskan fishing communities do exhibit an "active" portfolio management style, with substantial

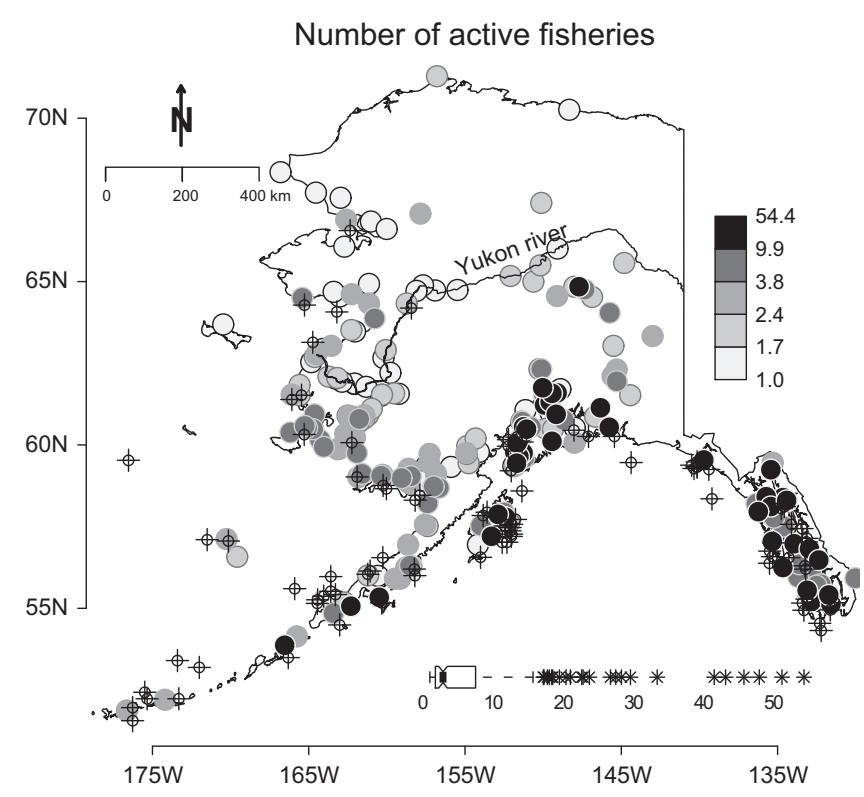

Fig. 3. Community fishing portfolio sizes based upon the number of active fisheries. Data are mean values across years and include only those communities with 7 or greater data points over $1990-2010(n=239)$. Breakpoints correspond to quintiles. Boxplots show a summary of the state-wide data with notches indicating the median metric value and 95\% confidence interval [34]. Crosshairs represent the approximate centers of fishing activity for Alaskan State-managed commercial fisheries over the study period (cf. [5]). 

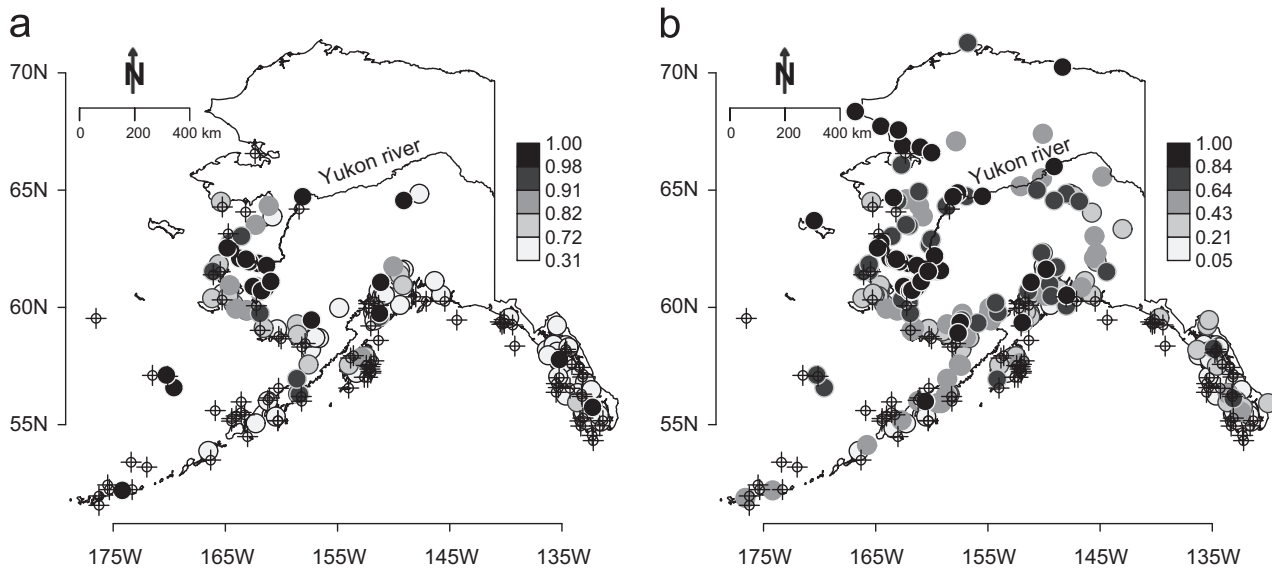

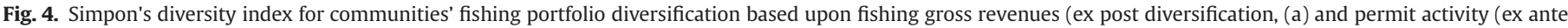

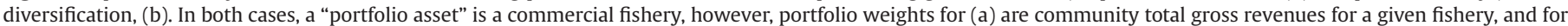

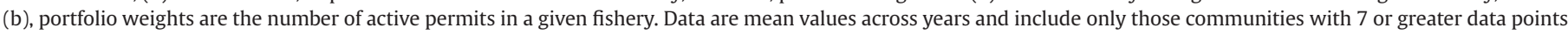

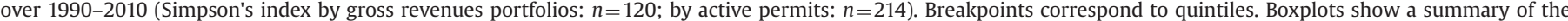

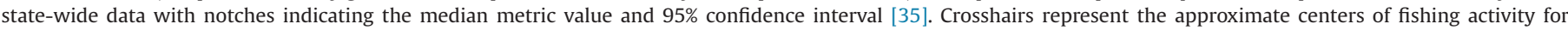
Alaskan State-managed commercial fisheries over the study period (cf. [5]).
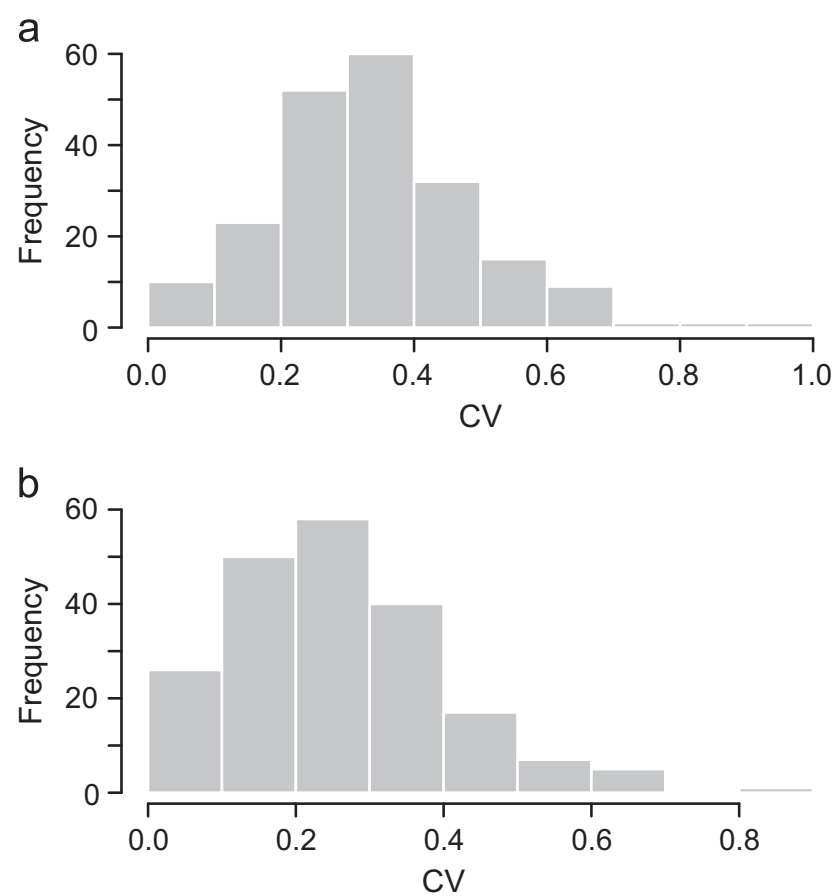

Fig. 5. Histograms of communities' coefficient of variation (CV) in (a) portfolio size (number of active fisheries, and (b) in portfolio diversification measured as Simpson's index based upon active permits (ex ante portfolio diversification) across 1990-2010. Data are coefficient of variation across years; only communities with 7 or more years of data during the study period are shown (active fisheries: $n=204$; Simpson's index based upon active permits: $n=214$ ).

year to year variation in the number of active fisheries (Fig. 5a) and in their ex ante portfolio diversification (Fig. 5b). Conversely, some communities exhibit a more "passive" portfolio management style with consistent numbers of active fisheries year to year and consistent diversification thereof. Incorporating measurements of portfolio management style into our analyses, however, is complicated by the fact that our proxies for management style - as measured by the CV of active fisheries and the CV of ex ante portfolio diversification over the sample period - suffer from: (i) imperfect measures of active or passive management, relative to measurements such as turnover rates used for evaluating mutual fund investment performance; and (ii) high collinearity with the set of predictors in our regression analysis. The role of portfolio management style in community-level fishing performance and variability remains an open question.

The data analyzed in this study demonstrate that the size and diversification of a community's fishing portfolio affects annual gross fishing revenues variability, and thereby presents an avenue through which fishing communities can reduce their exposure to economic risk. Policies that create entry barriers to commercial fisheries could therefore increase fishing communities' exposure to economic risk by impeding community residents from participating in a variety of fisheries. On the other hand, some communities may face inherent constraints on the set of fisheries with which to construct a portfolio of opportunities, particularly in regions of the state with fewer and more volatile local fisheries. The implication of this is that some communities may have limited ability to benefit from larger and/or more diverse fishing portfolios, limiting the policy options available to promote economic stability through larger and/or more diverse fishing portfolios. Furthermore, communities with location-constrained portfolio opportunities may be particularly susceptible to policies that affect catch or price variability, and alternative strategies for reducing exposure to economic risk may need to be considered instead. For instance, policies that promote new harvesting opportunities can provide a means for communities to increase the size and diversification of their fishery portfolio. Similarly, economic diversification can be enhanced through policies that facilitate the development of industries outside of wild capture fishing, thereby reducing fishing communities' dependence on commercial fishing revenues. We caution, however, that policies that promote the development of non-fishery sectors need carefully consider any potential negative externalities that may affect a community's set of fishing opportunities. For example, while aquaculture may provide a community with economic opportunities outside of capture fisheries, nearby wild fish populations may be at risk from parasites from farmed seafood pens [39]. In other cases, extractive resource harvest of minerals or timber can degrade fisheries habitat, potentially reducing the productivity of wild fish stocks [40-42]. Such negative externalities are therefore counterproductive and may attenuate - or in extreme cases, nullify - the benefits of diversifying outside of wild capture fishing. 


\section{Acknowledgements}

Funding for this work was provided by the North Pacific Research Board, project 1214. This is NPRB publication 479. We thank Marine Policy reviewers and editorial staff for comments that improved an earlier draft of this piece. The findings and conclusions in this article are those of the authors and do not necessarily represent the views of the State of Alaska or the U.S. Government.

\section{Appendix A. Supporting information}

Supplementary data associated with this article can be found in the online version at http://dx.doi.org/10.1016/j.marpol.2014.03. 027.

\section{References}

[1] Worm B, Hilborn R, Baum JK, Branch TA, Collie J, Costello C, et al. Rebuilding global fisheries. Science 2009;325:578-85.

[2] U.S. Department of Commerce (USDC). Magnuson-Stevens Fishery Conservation and Management Act as Amended through January, 2007. U.S. Public Law 109-479; 2007.

[3] Clay PM, Olsen J. Defining fishing communities: vulnerability and the Magnuson-Stevens Fishery Conservation and Management Act. Hum Ecol Rev 2008;15:143-260.

[4] Tuler S, Agyeman J, Pinto da Silva P, LoRusso KR, Kay R Assessing vulnerabilities: integrating information about driving forces that affect risks and resilience in fishing communities. Hum Ecol Rev, 200; 15 171-184.

[5] Sethi SA, Dalton M, Hilborn R. Quantitative risk measures applied to Alaskan commercial fisheries. Can J Fish Aquat Sci 2012;69:487-98.

[6] Knapp G. Local permit ownership in Alaska salmon fisheries. Mar Policy 2011;35:658-66.

[7] Hsieh CH, Reiss CS, Hunter JR, Beddington JR, May RM, Sugihara G. Fishing elevates variability in the abundance of exploited species. Nature 2006;443:859-62.

[8] Blank SC. Producers get squeezed up the farming food chain: a theory of crop portfolio composition and land use. Rev Agric Econ 2001;23:404-22.

[9] Heady E. Diversification in resource allocation and minimization of income variability. J. Farm Econ. 1952;34:482-96.

[10] Lowe ME, Carothers C, editors. Bethesda, MD: American Fisheries Society; 2008.

[11] Jentoft S. The community: a missing link in fisheries management. Mar Policy 2000;24:53-9.

[12] Sepez JA, Tilt BD, Package CL, Lazrus HM, Vaccro I Community Profiles for North Pacific Fisheries-Alaska. NOAA Technical Memorandum NMFS-AFSC$160 ; 2005$.

[13] Kasperski S, Holland DS. Income diversification and risk for fishermen. Proc Nat Acad Sci 2013;110:2076-81.

[14] Trenkel VM, Daure's F, Rochet M-J, Lorance P. Interannual variability of fisheries economic returns and energy ratios is mostly explained by gear type. PLoS One 2013;8(7):e70165.

[15] Minnegal M, Dwyer PD. Managing risk, resisting management: stability and diversity in a southern Australian fishing fleet. Hum Organiz 2008;67:97-108.
[16] van Oostenbrugge JAE, Bakker EJ, van Densen WLT, Machiels MAM. van Zwieten PAM. Characterizing catch variability in a multispecies fishery: implications for fishery management. Can J Fish Aquat Sci 2002;59:1032-43.

[17] Samuelson PA. Efficient portfolio selection for Pareto-Lévy investments. J Finan. Quantum Anal 1967;2:107-22.

[18] Elton EJ, Gruber MJ, Brown SJ, Goetzmann WN. Modern portfolio theory and investment analysis. New York: Wiley; 2009.

[19] Sethi SA, Riggs W, Knapp G. Metrics to monitor the status of fishing communities: an Alaska state of the State retrospective 1980-2010. Ocean Coast Manage 2014;88:21-30.

[20] Shriver J, Gho M, Iverson K, Farrington C Changes in the distribution of Alaska's commercial fisheries entry permits, 1975-2011. Commercial fisheries entry commission report number 12-1 N-EXEC; 2012.

[21] Simpson EH. Measurement of diversity. Nature 1949;163:688.

[22] Rockafellar RT, Uryasev S. Conditional value at risk for general loss distributions. J. Banking Finance 2002;26:1443-71.

[23] Andersson F, Mausser H, Rosen D, Uryasev S. Credit risk optimization with conditional value at risk criterion. Math Program 2001;89:273-91.

[24] R Development Core Team (RDCT). R: A language and environment for statistical computing. Vienna: R foundation for statistical computing; 2013.

[25] Sethi SA, Dalton M. Risk measures for natural resource management: description, simulation testing and $\mathrm{R}$ code with fisheries examples. J Fish Wildl Manage 2012;3:150-7.

[26] Hare S, Mantua NJ. Empirical evidence for North Pacific regime shits in 1977 and 1989. Prog Oceanogr 2000;47:103-45.

[27] Breiman L. Random forests. Mach Learn 2001;45:5-32.

[28] Breiman L, Friedman J, Olshen R, Stone C. Classification and regression trees. Belmont, CA: Wadsworth International Group; 1984.

[29] Farawy JJ. Extending the Linear Model with R: Generalized linear, mixed effects and nonparametric regression models. 2006.

[30] Genuer R, Poggi JM, Tuleau-Malot C. Variable selection using random forests. Pattern Recogn Lett 2010;31:2225-36.

[31] Zhang H, Singer B. Recursive partitioning in the health sciences. New York: Springer; 1999.

[32] Friedman J. Greedy function approximation: a gradient boosting machine. Ann Stat 2001;29:1189-232.

[33] Liaw A, Wiener M Classification and regression by randomforest. R News 2002; $2: 18-22$

[34] McGill R, Tukey J, Larsen W. Variations of box plots. Am Stat 1978;32:12-6.

[35] Hilborn R, Quinn TP, Schindler D, Rogers DE. Biocomplexity and fisheries sustainability. Proc Nat Acad Sci 2003;100:6564-8.

[36] Schindler DE, Hilborn R, Chasco B, Boatright CP, Quinn TP, Rogers LA, et al. Population diversity and the portfolio effect in an exploited species. Nature 2010;465:609-12.

[37] Sethi SA, Dalton M, Hilborn R. Managing harvest risk with catch-pooling cooperatives. ICES J Mar Sci 2012;69:1038-44.

[38] Shukla R. The value of active portfolio management. J Econ Bus 2004;56:331-46.

[39] Costello MJ. How seal lice from salmon farms may cause wild salmonid declines in Europe and North America and be a threat to fishes elsewhere. Proc R Soc London, Ser B 2009;276:3385-94.

[40] Barry KL, Grout JA, Levings CD, Nidle BH, Piercey GE. Impacts of acid mine drainage on juvenile salmonids in an estuary near Britannia Beach in Howe Sound British Columbia. Can J Fish Aquat Sci 2000;57:2031-43.

[41] Heifetz J, Murphy ML, Koski KV. Effects of logging on winter habitat of juvenile salmonids in Alaskan streams. N Am J Fish Manage 1986;6:52-8.

[42] Olsen JB, Spearman WJ, Sage WG, Miller SJ, Flannery BG, Wenburg JK. Variation in the population structure of Yukon River chum and coho salmon: evaluating the potential impact of localized habitat degradation. Trans Am Fish Soc 2004;133:476-83. 